\title{
Donepezil reverses buprenorphine-induced central respiratory depression in anesthetized rabbits
}

\author{
SHIGEKI SAKURABA ${ }^{1,2}$, MIKI TSUJTAA $^{2}$, HIROFUMI ARISAKA $^{1}$, JUNZO \\ TAKEDA $^{2}$, KAZUICHI YOSHIDA ${ }^{1}$, SHUN-ICHI KUWANA $^{3,4}$
}

${ }^{1}$ Department of Anesthesiology, Clinical Care Medicine, Kanagawa Dental College, Kanagawa.
2 Department of Anesthesiology, School of Medicine, Keio University, Tokyo.
${ }^{3}$ Department of Physiology, Faculty of Health Sciences, Uekusa Gakuen University, Chiba.
${ }^{4}$ Department of Physiology, School of Medicine, Teikyo University, Tokyo, Japan.

\begin{abstract}
Buprenorphine is a mixed opioid receptor agonist-antagonist used in acute and chronic pain management. Although this agent's analgesic effect increases in a dose-dependent manner, buprenorphine-induced respiratory depression shows a marked ceiling effect at higher doses, which is considered to be an indicator of safety. Nevertheless, cases of overdose mortality or severe respiratory depression associated with buprenorphine use have been reported. Naloxone can reverse buprenorphine-induced respiratory depression, but is slow-acting and unstable, meaning that new drug candidates able to specifically antagonize buprenorphine-induced respiratory depression are needed in order to enable maximal analgesic effect without respiratory depression. Acetylcholine is an excitatory neurotransmitter in central respiratory control. We previously showed that a long-acting acetylcholinesterase inhibitor, donepezil, antagonizes morphine-induced respiratory depression. We have now investigated how donepezil affects buprenorphine-induced respiratory depression in anesthetized, paralyzed, and artificially ventilated rabbits. We measured phrenic nerve discharge as an index of respiratory rate and amplitude, and compared discharges following the injection of buprenorphine with discharges following the injection of donepezil. Buprenorphine-induced suppression of the respiratory rate and respiratory amplitude was antagonized by donepezil $(78.4 \pm 4.8 \%, 92.3 \% \pm 22.8 \%$ of control, respectively). These findings indicate that systemically administered donepezil restores buprenorphine-induced respiratory depression in anesthetized rabbits.
\end{abstract}

Key terms: buprenorphine, donepezil, rabbit, respiratory depression, cholinesterase inhibitor.

\section{INTRODUCTION}

Opioid analgesics are among the most effective agents currently available for treating postoperative and chronic pain. Apart from their analgesic actions, all opiates induce various side effects (Bowdle, 1998; Gan, 2006), of which respiratory depression is the most serious and potentially life-threatening (Bailey et al., 2000). Fentanyl and morphine, both $\mu$ opioid agonists, are widely and frequently used for acute and chronic pain treatment (Trescot et al., 2008). Both of these opioids are high-efficacy full agonists of the $\mu$ - opioid receptor, characterized by a narrow therapeutic window, and thus careful titration is required in order to achieve optimal analgesic effect without inducing side effects (Dahan et al., 2005). In contrast, buprenorphine is a potent analgesic that acts as a partial agonist of the $\mu$-opioid and opioid receptor-like 1 receptors, and shows antagonism for the $\kappa$ opioid receptor (Lutfy et al., 2003). Its partial agonistic activity is generally believed to explain its greater safety, by virtue of the ceiling effect it exhibits with regard to $\mu$-opioid receptor-mediated respiratory depression (Walsh et al., 1994;

\footnotetext{
* Corresponding author: Shigeki Sakuraba, M.D., Ph.D., Department of Anesthesiology, Clinical Care Medicine, Kanagawa Dental College, 82 Inaoka-cho, Yokosuka, Kanagawa 238-8580, Japan, Tel/Fax: +81-4-6822-8842, Email: shigekisakuraba@gmail.com
} 
Dahan et al., 2005; Dahan et al., 2006). Buprenorphine's analgesic effect increases in a dose-dependent manner (Dahan et al., 2006), has a long duration of action, and the discontinuation of its use appears to elicit only limited withdrawal symptoms (Cowan et al., 1977; Dum et al., 1981). Given these pharmacological properties, the comparative safety advantage of buprenorphine over other opiate agents stands as a compelling rationale for its use in many clinical applications. Nevertheless, various cases of overdose mortality or severe respiratory depression (Zanette et al., 1996; Reynaud et al., 1998; Moro et al., 2006; Schwarz et al., 2007) associated with buprenorphine use have been reported.

Buprenorphine-induced side effects can be treated with naloxone, an opioid receptor antagonist, but the reversal effects do not occur immediately and do not reach a peak until three hours after administration, due to its relative inability to displace buprenorphine that has already bound to opioid receptors (Gal, 1989). Buprenorphine-induced respiratory depression may also outlast the effects of naloxone (van Dorp et al., 2006). For these reasons, alternative agents capable of reversing buprenorphine-induced respiratory depression are required to improve its safety profile.

In our previous study, it was shown that donepezil, a long-acting synthetic drug widely used for Alzheimer's disease (Rho and Lipson, 1997), can reverse morphineinduced respiratory depression (Tsujita et al., 2007).

In the present study, using anesthetized rabbits as a model, we have investigated whether donepezil can counteract buprenorphine-induced respiratory depression.

\section{METHODS}

\section{General}

This study was conducted in accordance with a protocol approved by the Animal Care and Use Committee of Teikyo University School of Medicine. The experimental procedure has been described in detail elsewhere (Kuwana and Natsui, 1981; Okada et al 2004; Tsujita et al. 2007). Briefly, 15 healthy rabbits (Japanese White, male, Sankyo laboratory, Tokyo, Japan) $2.35 \pm 0.08 \mathrm{~kg}(1.98-2.97 \mathrm{~kg})$ were anesthetized by intraperitoneal administration of $10 \mathrm{mg} / \mathrm{kg}$ ketamine (Sankyo Pharmaceutical, Tokyo, Japan) followed by intravenous administration of $40 \mathrm{mg} / \mathrm{kg}$ chloralose and $200 \mathrm{mg} / \mathrm{kg}$ urethane (Wako Pure Chemical, Osaka, Japan). In our previous study, the combination of chloralose and urethane maintained stable depth of anesthesia for over 8 h (Okada et al. 2004); no experiment in the present study lasted more than $3 \mathrm{~h}$. After anesthesia was induced, each rabbit was placed in a supine position on an electrical heating pad, and rectal temperature was maintained at $37-38{ }^{\circ} \mathrm{C}$. The trachea was cannulated in the midcervical region for artificial respiration, and end-tidal $\mathrm{CO}_{2}\left(\mathrm{EtCO}_{2}\right)$ was monitored continuously with a gas analyzer (Respina 1H26, NEC San-Ei, Tokyo, Japan). The right femoral artery and vein were catheterized to arterial blood pressure measurement and intravenous injection. The common carotid artery was exposed where the connective tissue between the trachea and the sternocleidomastoid muscle were cautiously eliminated. The vagus and aortic nerves were found next to the common carotid artery and sectioned bilaterally at the mid-cervical region. Muscle paralysis was induced with $0.2 \mathrm{mg} /$ $\mathrm{kg}$ pancuronium bromide (Sankyo Pharmaceutical, Tokyo, Japan) injected into the right femoral vein, and artificial ventilation with room air was initiated. The same dose of pancuronium bromide was administered hourly thereafter. Spontaneous respiration was completely inhibited during the experiment. $\mathrm{EtCO}_{2}$ was maintained at $35 \pm 3 \mathrm{mmHg}$ by adjusting the respiratory frequency (40-60 breaths/min) and the tidal volume $(20-50 \mathrm{ml} / \mathrm{breath})$ of the ventilator (Kuwana and Natsui, 1981). P h r e n i c nerve discharge was used as an index of central respiratory output (Kuwana and Natsui, 1981). The right phrenic nerve was sectioned at the low cervical region, and the 
central section end was placed on a bipolar platinum electrode in a pool of liquid paraffin. The phrenic nerve discharge was amplified using an AC amplifier (AB651J, Nihon Kohden, Tokyo) and passed through a band-pass filter $(50 \mathrm{~Hz}-3 \mathrm{kHz})$. It was then half-wave rectified and integrated with a time constant of $100 \mathrm{~ms}$ with a signalintegrator (EI601G, Nihon Kohden, Tokyo). Signals of raw phrenic discharge, integrated phrenic output, $\mathrm{EtCO}_{2}$ and arterial blood pressure were recorded using a thermal array recorder (RTA-1200M, Nihon Kohden, Tokyo). Signal data were stored on a digital tape recorder (RD-135T, TEAC, Tokyo) for subsequent analysis.

Respiratory rate was calculated as the number of phrenic nerve discharge per minute. Amplitude of integrated phrenic activity was shown as the percentage of control. Minute phrenic activity was calculated as the multiplication of respiratory rate and amplitude of integrated phrenic activity and was shown as the percentage of control.

\section{Protocol}

At about 30 min after surgery, respiratory rate (breaths/min) and respiratory amplitude (height of integrated phrenic output) were measured to provide control or baseline indices. These were also measured at 10 min after the intravenous injection of 0.02 $\mathrm{mg} / \mathrm{kg}$ buprenorphine over a period of 1-2 $\mathrm{min}$. Then, after the signal became stable, 4 $\mathrm{ml} / \mathrm{kg}$ saline $(\mathrm{n}=6)$ or $0.4 \mathrm{mg} / \mathrm{kg}$ donepezil $(n=6)$ was injected, and both indices were also measured $15 \mathrm{~min}$ after the injection of these drugs. In the preliminary study $(\mathrm{n}=$ $3)$, various doses $(0.01 \mathrm{mg} / \mathrm{kg}, 0.02 \mathrm{mg} / \mathrm{kg}$, $0.04 \mathrm{mg} / \mathrm{kg}$ ) of buprenorphine were administered to confirm whether $0.02 \mathrm{mg} /$ $\mathrm{kg}$ buprenorphine is sufficient to induce respiratory depression (Shafford and Schadt, 2008) (Fig. 1). To assess the central effect of these drugs, experiments were performed in rabbits with denervated peripheral chemoreceptors. The carotid sinus nerves on both sides were sectioned at the level of their emergence from the glossopharyngeal nerves. In most cases more than $1 \mathrm{~h}$ had to be allowed for subsidence of neurogenic hypertension brought about by the simultaneous denervation of the carotid sinus baroreceptors prior to beginning our experimental observations. At the end of the experiment, the animal was sacrificed with intravenous injection of $\mathrm{KCl}$.
Control

Integ. Phrenic N

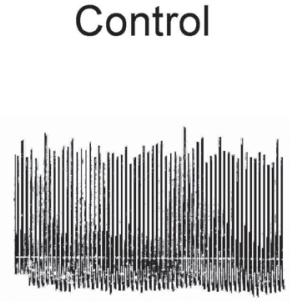

$0.01 \mathrm{mg} / \mathrm{kg}$

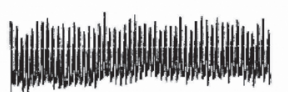

Buprenorphine

$$
0.02 \mathrm{mg} / \mathrm{kg} \quad 0.04 \mathrm{mg} / \mathrm{kg}
$$

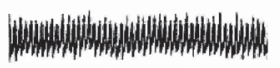

$\mathrm{EtCO}_{2}(\%){ }_{0}^{5}[$

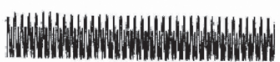

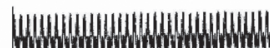

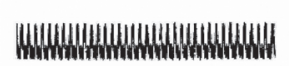

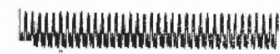

$20 \mathrm{sec}$

Fig. 1: Representative recording of integrated phrenic nerve activity, showing effects at various doses $(0.01 \mathrm{mg} / \mathrm{kg}, 0.02 \mathrm{mg} / \mathrm{kg}, 0.04 \mathrm{mg} / \mathrm{kg})$ of buprenorphine. End-tidal $\mathrm{CO}_{2}(\%)$ was continuously monitored, and is shown at the bottom of the figure.

Integ. Phrenic N: Integrated phrenic nerve activity

$\mathrm{EtCO}_{2}$ : End-tidal $\mathrm{CO}_{2}$ 


\section{Statistical analysis}

Respiratory frequency and respiratory amplitude after injection of buprenorphine and after injection of saline or donepezil were both analyzed using a paired t-test. $P$ $<0.05$ was considered significant. Data are expressed as mean $\pm \mathrm{SE}$.

\section{RESULTS}

Buprenorphine $(0.02 \mathrm{mg} / \mathrm{kg})$ administration significantly decreased mean respiratory rate from $106.0 \pm 4.0$ breaths $/ \mathrm{min}$ to $53.8 \pm$ 7.8 breaths $/ \mathrm{min}$, amplitude of integrated phrenic nerve activity to $43.8 \pm 7.8 \%$ of control and minute phrenic activity to 26.4 $\pm 7.1 \%$ of control $(\mathrm{n}=12)$.

The buprenorphine-induced reductions in each index were partly recovered following administration of donepezil (Fig. $2)$. Donepezil induced significant increments in (a) respiratory rate to $87.0 \pm$ 8.5 breaths $/ \mathrm{min}$ from $44.0 \pm 14.3$ breaths/ $\min (P<0.05$; Fig. $3 \mathrm{~A})$, in (b) respiratory amplitude to $92.3 \pm 22.8 \%$ of control from $21.2 \pm 8.0 \%(P<0.05$; Fig. $3 \mathrm{~B})$, and in $(\mathrm{c})$ minute phrenic activity to $72.6 \pm 18.5 \%$ of control from $12.9 \pm 5.5 \%(P<0.05$; Fig. 2C). Injection of saline did not induce any changes in phrenic nerve activity. Systolic blood pressure did not change significantly during these experiments.

\section{DISCUSSION}

We studied whether systemically administered donepezil, an acetylcholinesterase inhibitor, is effective in counteracting buprenorphineinduced respiratory depression in anesthetized rabbits. We found that donepezil alleviates buprenorphine-induced respiratory depression, without any effects on $\mathrm{EtCO}_{2}$ or systolic blood pressure.

Control Donepezil

After 10min

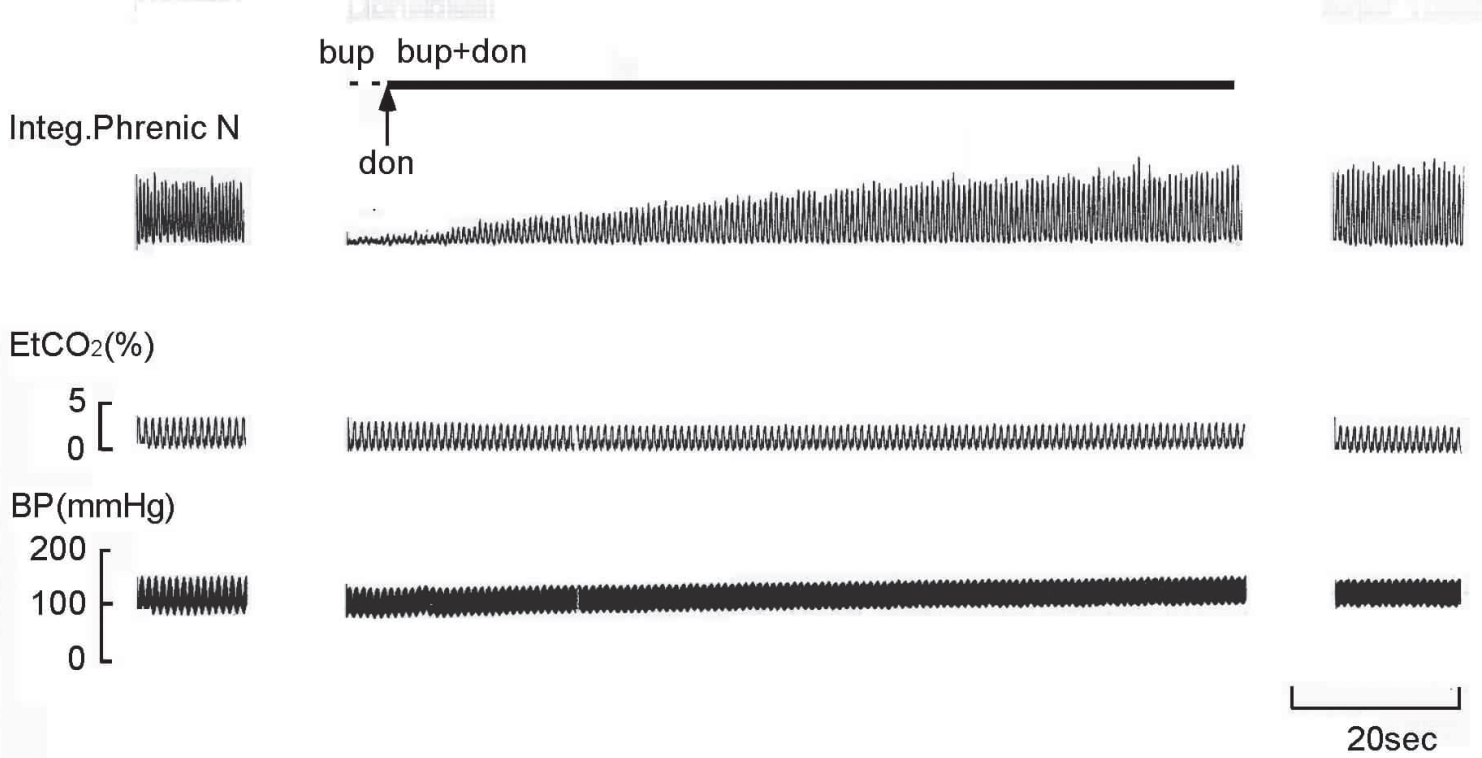

Fig. 2: Representative recording of effects of donepezil on buprenorphine-induced respiratory depression. End-tidal $\mathrm{CO}_{2}(\%)$ and blood pressure $(\mathrm{mmHg})$ were continuously monitored, and are shown at the bottom of the figure.

bup: buprenorphine, don: donepezil

Integ. Phrenic N: Integrated phrenic nerve activity

$\mathrm{EtCO}_{2}$ : End-tidal $\mathrm{CO}_{2}$

BP: blood pressure 
The respiratory depression induced by most $\mu$-opioid receptor agonists, such as morphine and alfentanil, is easily and immediately reversed by naloxone (Bowdle 1998; Sarton et al., 2008), but simultaneously inhibits opioid-induced analgesia (Bowdle, 1998). Naloxone has no effect on reversing analgesia induced by buprenorphine (Paronis and Holtzman, 1991) but does partially counteract buprenorphine-induced respiratory depression. However, naloxone is a suboptimal solution to alleviate buprenorphine-induced respiratory depression because naloxone has a shorter duration of action than buprenorphine (Gal, 1989; von Dorp et al., 2006; Sarton et al., 2008) and reaches peak effectiveness slowly (Gal, 1989). Doxapram, a respiratory stimulant, has been used to overcome buprenorphine-induced respiratory depression (Orwin, 1977; Flecknell et al., 1989), however, this effect is short lived (Orwin, 1977). Therefore, the effects of donepezil on buprenorphineinduced respiratory depression should be investigated in clinical settings.

Donepezil is a reversible inhibitor that exhibits high specificity for centrally active acetylcholinesterase and raises acetylcholine (ACh) levels in the brain (Rho and Lipson, 1997; Rogers et al., 1998). ACh is an excitatory neurotransmitter involved in central respiratory control (Murakoshi et al., 1985; Monteau et al., 1990; Shao and Feldman, 2000 , 2005), suggesting that donepezilinduced increases of $\mathrm{ACh}$ in central respiratory control may reverse buprenorphine-induced respiratory depression.

In rabbits, the recommended dose range of buprenorphine for analgesia is 0.01-0.05 $\mathrm{mg} / \mathrm{kg}$ (Dobromylskyj et al., 2000). However, in human volunteers, the onset of respiratory depression is more rapid than the onset of analgesia (Dahan et al., 2006), indicating that respiratory depression may
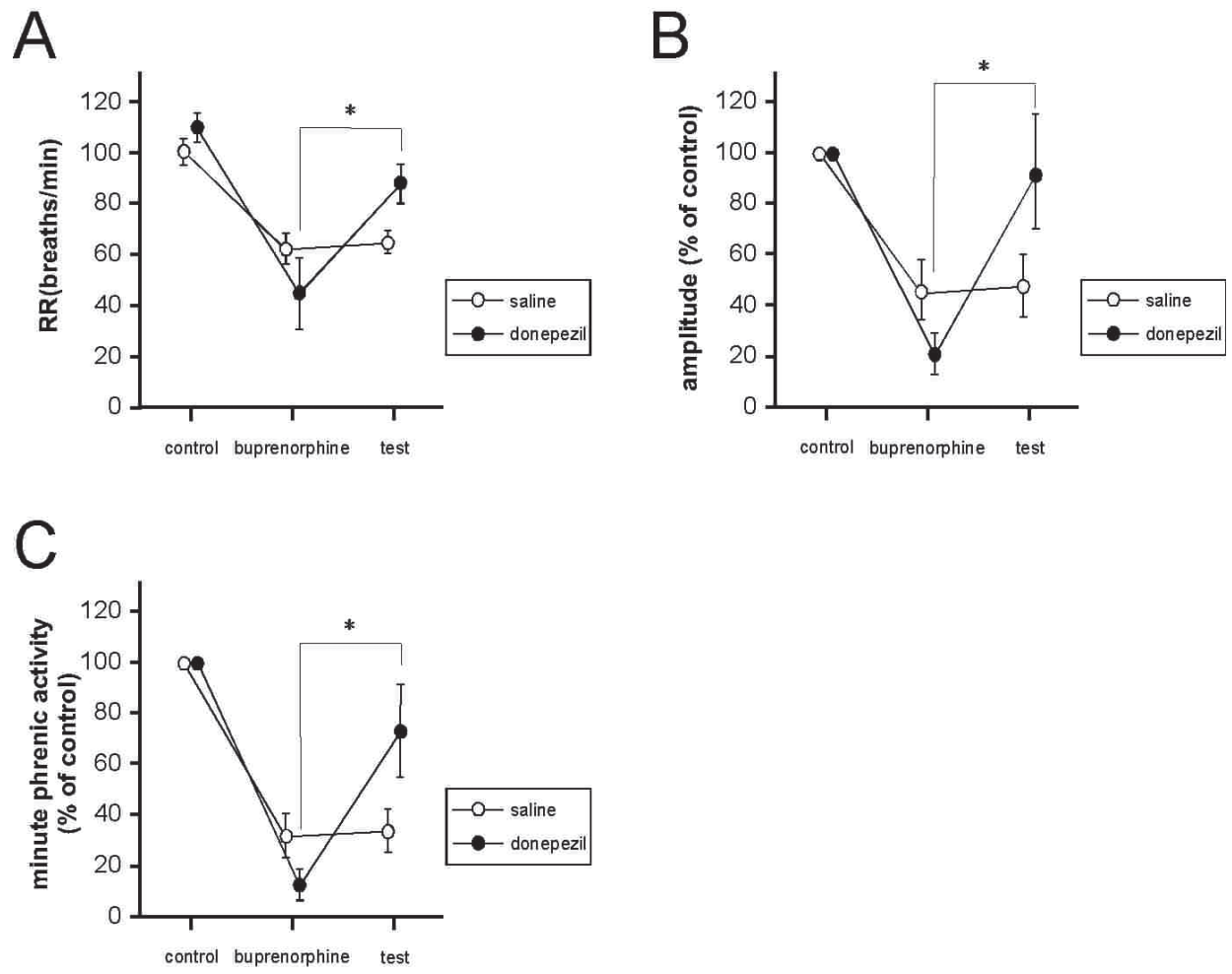

Fig. 3: Effects of intravenous test drugs (donepezil or saline) on buprenorphine-induced respiratory depression including (A) respiratory rate (breaths/min), (B) amplitude (\% of control), (C) minute phrenic activity (\% of control), $* P<0.05 \mathrm{RR}$ : respiratory rate 
be induced by buprenorphine at lower doses than those associated with induction of analgesia (Shafford and Schadt, 2008). Even in a previous study using conscious rabbits, intravenous administration of 0.02 $\mathrm{mg} / \mathrm{kg}$ buprenorphine induced about $75 \%$ reduction of control respiratory rate at 10 min after buprenorphine administration (Shafford and Schadt, 2008). In our study, we tested anesthetized rabbits, which may be more susceptible to respiratory depression than conscious rabbits due to the co-administration of anesthetics (Pirnay et al., 2008). Although the results of the previous study in conscious rabbits indicated that $0.02 \mathrm{mg} / \mathrm{kg}$ buprenorphine causes near-complete respiratory depression (Shafford and Schadt, 2008), in our study, we found that buprenorphine induced a milder reduction of respiratory rate to about $54 \%$ of control. This discrepancy may be attributable to the different timing (in conscious vs. anesthetized animals) of evaluating the baseline respiratory rate (306 breaths/min vs. 106 breaths $/ \mathrm{min}$ ).

Previous study suggests that donepezil at $0.25 \mathrm{mg} / \mathrm{kg}$ inhibits $\sim 55 \%$ of the acetylcholinesterase activity in living monkeys (Shiraishi et al., 2005). To achieve a greater inhibitory effect, we used $0.4 \mathrm{mg} /$ $\mathrm{kg}$ donepezil in the current study. It is reported that the maximal increase in intracerebral ACh levels occurs as early as 14 min after intravenous injection of donepezil in monkeys (Tsukada et al., 2004). Although these previous reports support the assumption that the concentration of donepezil in the brain should reach a steady state before the measurement of indices in the present study (after $15 \mathrm{~min}$ ), donepezil only partially alleviated the morphine-induced respiratory depression, indicating that further studies will be needed to evaluate the dosedependent effects of donepezil on buprenorphine-induced respiratory depression.

In summary, the inhibitory effects of buprenorphine on respiratory rate and amplitude are partly recovered by donepezil in anesthetized rabbit. These effects might be caused by an increase in the release of $\mathrm{ACh}$ in the respiratory center.

\section{ACKNOWLEDGEMENTS}

This research was supported, in part, by the Keio Gijuku Postgraduate School Fund for the Advancement of Research, the Keio University Grant-in-Aid for Encouragement of Young Medical Scientists, and a Grantin-Aid for Young Scientists (B) (21791479) from Japan Society for the Promotion of Science.

\section{REFERENCES}

BAILEY PL, LU JK, PACE NL, ORR JA, WHITE JL, HAMBER EA, SLAWSON MH, CROUCH DJ, ROLLINS DE (2000) Effects of intrathecal morphine on the ventilatory response to hypoxia. N Engl J Med 343: $1228-1234$

BOWDLE TA (1998) Adverse effects of opioid agonists and agonist-antagonists in anaesthesia. Drug Saf. 19: 173-189

COWAN A, LEWIS JW, MACFARLANE IR (1977) Agonist and antagonist properties of buprenorphine, a new antinociceptive agent. Br J Pharmacol 60: 537-545

DAHAN A, YASSEN A, BIJL H, ROMBERG R, SARTON E, TEPPEMA L, OLOFSEN E, DANHOF M (2005) Comparison of the respiratory effects of intravenous buprenorphine and fentanyl in humans and rats. Br J Anaesth 94: 825-834

DAHAN A, YASSEN A, ROMBERG R, SARTON E, TEPPEMA L, OLOFSEN E, DANHOF M (2006) Buprenorphine induces ceiling in respiratory depression but not in analgesia. Br J Anaesth 96: 627632

DOBROMYLSKYJ P, FLECKNELL PA, LASCELLES BD, PASCOE PJ, TAYLOR P, WATERMANPEARSON A (2000) Management of postoperative and other acute pain. In: FLECKNELL PA, WATERMANPEARSON A (eds) Pain management in animals. London: WB Saunders. pp: 81-145

DUM J, BLÄSIG J, HERZ A (1981) Buprenorphine: demonstration of physical dependence liability. Eur J Pharmacol 70: 293-300

FLECKNELL PA, LILES JH, WOOTTON R (1989) Reversal of fentanyl/fluanisone neuroleptanalgesia in the rabbit using mixed agonist/antagonist opioids. Lab Anim 23: 147-155

GAL TJ (1989) Naloxone reversal of buprenorphineinduced respiratory depression. Clin Pharmacol Ther 45: $66-71$

GAN TJ (2006) Risk factors for postoperative nausea and vomiting. Anesth Analg 102: 1884-1898

KUWANA S, NATSUI T (1981) Effect of arterial $\left[\mathrm{H}^{+}\right]$on threshold $\mathrm{PCO}_{2}$ of the respiratory system in vagotomized and carotid sinus nerve denervated cats. J Physiol 318: 223-237

LUTFY K, EITAN S, BRYANT CD, YANG YC, SALIMINEJAD N, WALWYN W, KIEFFER BL, TAKESHIMA H, CARROLL FL, MAIDMENT NT, EVANS CJ (2003) Buprenorphine-induced antinociception is mediated by $\mu$-opioid receptors and compromised by concomitant activation of opioid receptor-like receptors. J Neurosci 23: 10331-10337

MONTEAU R, MORIN D, HILAIRE G (1990) 
Acetylcholine and central chemosensitivity: in vitro study in the newborn rat. Respir Physiol 81: 241-254

MORO C, TAINO R, MANDALA M, LABIANCA R (2006) Buprenorphine-induced acute respiratory depression during ifosfamide-based chemotherapy. Ann Oncol 17: 1466-1467

MURAKOSHI T, SUZUE T, TAMAI S (1985) A pharmacological study on respiratory rhythm in the isolated brainstem-spinal cord preparation of the newborn rat. Br J Pharmacol 86: 95-104

OKADA Y, SATOH T, KUWANA S, KASHIWAGI M, KUSAKABE T (2004) Electrical stimulation of the rabbit pulmonary artery increases respiratory output. Respir Physiol Neurobiol 140: 209-217

ORWIN JM (1977) The effect of doxapram on buprenorphine induced respiratory depression. Acta Anaesthesiol Belg 28: 93-106

PARONIS CA, HOLTZMAN SG (1991) Increased analgesic potency of mu agonists after continuous naloxone infusion in rats. $\mathrm{J}$ Pharmacol Exp Ther 259: 582-589

PIRNAY SO, MÉGARNBANE B, BORRON SW, RISÈDE P, MONIER C, RICORDEL I, BAUD FJ (2008) Effects of various combinations of benzodiazepines with buprenorphine on arterial blood gases in rats. Basic Clin Pharmacol Toxicol 103: 228-239

REYNAUD M, PETIT G, POTARD D, COURTY P (1998) Six deaths linked to concomitant use of buprenorphine and benzodiazepines. Addiction 93: 1385-1392

RHO JP, LIPSON LG (1997) Focus on donepezil: a reversible acetylcholinesterase inhibitor for the treatment of Alzheimer's disease. Formulary 32: 677678

ROGERS SL, DOODY RS, MOHS RC, FRIEDHOFF LT (1998) Donepezil improves cognition and global function in Alzheimer disease: a 15-week, doubleblind, placebo-controlled study. Donepezil Study Group. Arch Intern Med 158: 1021-1031

SARTON E, TEPPEMA L, DAHAN A (2008) Naloxone reversal of opioid-induced respiratory depression with special emphasis on the partial agonist/antagonist buprenorphine. Adv Exp Med Biol 605: 486-491

SCHWARZ KA, CANTRELL FL, VOHRA RB, CLARK RF (2007) Suboxone (buprenorphine/naloxone) toxicity in pediatric patients: a case report. Pediatr Emerg Care 23: 651-652

SHAFFORD HL, SCHADT JC (2008) Respiratory and cardiovascular effects of buprenorphine in conscious rabbits. Vet Anaesth Analg 35: 326-332

SHAO XM, FELDMAN JL (2000) Acetylcholine modulates respiratory pattern: effects mediated by M3like receptors in preBötzinger complex inspiratory neurons. J Neurophysiol 83: 1243-1252

SHAO XM, FELDMAN JL (2005) Cholinergic neurotransmission in the preBötzinger Complex modulates excitability of inspiratory neurons and regulates respiratory rhythm. Neuroscience 130: 10691081

SHIRAISHI T, KIKUCHI T, FUKUSHI K, SHINOTOH H, NAGATSUKA S, TANAKA $\mathrm{N}$, OTA T, SATO K, HIRANO S, TANADA S, IYO M, IRIE T (2005) Estimation of Plasma IC50 of donepezil hydrochloride for brain acetylcholinesterase inhibition in monkey using $\mathrm{N}-[11 \mathrm{C}]$ methylpiperidin-4-yl acetate ([11C]MP4A) and PET. Neuropsychopharmacology 30: 2154-2161

TRESCOT AM, DATTA S, LEE M, HANSEN H (2008) Opioid pharmacology. Pain Physician 11: S133-153

TSUJITA M, SAKURABA S, KURIBAYASHI J, HOSOKAWA Y, HATORI E, OKADA Y, KASHIWAGI M, TAKEDA J, KUWANA S (2007) Antagonism of morphine-induced central respiratory depression by donepezil in the anesthetized rabbit. Biol Res 40: 339-346

TSUKADA H, NISHIYAMA S, FUKUMOTO D, OHBA $\mathrm{H}$, SATO K, KAKIUCHI T (2004) Effects of acute acetylcholinesterase inhibition on the cerebral cholinergic neuronal system and cognitive function: Functional imaging of the conscious monkey brain using animal PET in combination with microdialysis. Synapse 52: 1-10

VAN DORP E, YASSEN A, SARTON E, ROMBERG R, OLOFSEN E, TEPPEMA L, DANHOF M, DAHAN A (2006) Naloxone reversal of buprenorphine-induced respiratory depression. Anesthesiology 105: 51-57

WALSH SL, PRESTON KL, STITZER ML, CONE EJ, BIGELOW GE (1994) Clinical pharmacology of buprenorphine: ceiling effects at high doses. Clin Pharmacol Ther 55: 569-580

ZANETTE G, MANANI G, GIUSTI F, PITTONI G, ORI C (1996) Respiratory depression following administration of low dose buprenorphine as postoperative analgesic after fentanyl balanced anaesthesia. Paediatr Anaesth 6: 419-422 
